\title{
Small Intestine Cancer TNM Finding v8
}

National Cancer Institute

\section{Source}

National Cancer Institute. Small Intestine Cancer TNM Finding v8. NCI Thesaurus. Code C133825.

A finding about one or more characteristics of small intestine cancer, following the rules of the TNM AJCC v8 classification system. This staging system applies to carcinomas of the nonampullary duodenum, jejunum, and ileum. Only adenocarcinomas are assigned a stage group. Nonadenocarcinomas arising in the small intestine should have a TNM assigned but are not assigned a stage classification. (from AJCC 8th Ed.) 